\title{
Review Article \\ The Patient's Experience of the Psychosocial Process That Influences Identity following Stroke Rehabilitation: A Metaethnography
}

\author{
E. Hole, ${ }^{1}$ B. Stubbs, ${ }^{2}$ C. Roskell, ${ }^{1}$ and A. Soundy ${ }^{1}$ \\ ${ }^{1}$ Department of Physiotherapy, University of Birmingham, 52 Pritchatts Road, Edgbaston, Birmingham B15 2TT, UK \\ ${ }^{2}$ School of Health and Social Care, University of Greenwich, London SE10 9LS, UK \\ Correspondence should be addressed to A. Soundy; a.a.soundy@bham.ac.uk
}

Received 12 August 2013; Accepted 19 October 2013; Published 28 January 2014

Academic Editors: G. Caruso and Y.-P. Hou

Copyright (c) 2014 E. Hole et al. This is an open access article distributed under the Creative Commons Attribution License, which permits unrestricted use, distribution, and reproduction in any medium, provided the original work is properly cited.

Background and Purpose. Patient experience is increasingly being recognised as a key health outcome due to its positive correlation with quality of life and treatment compliance. The aim of this study was to create a model of how patient's experiences of rehabilitation after stroke influence their outcome. Methods. A metaethnography of qualitative articles published since 2000 was undertaken. A systematic search of four databases using the keywords was competed. Original studies were included if at least $50 \%$ of their data from results was focused on stroke survivors experiences and if they reflected an overarching experience of stroke rehabilitation. Relevant papers were appraised for quality using the COREQ tool. Pata analysis as undertaken using traditional processes of extracting, interpreting, translating, and synthesizing the included studies. Results. Thirteen studies were included. Two themes (1) evolution of identity and (2) psychosocial constructs that influence experience were identified. A model of recovery was generated. Conclusion. The synthesis model conceptualizes how the recovery of stroke survivors' sense of identity changes during rehabilitation illustrating changes and evolution over time. Positive experiences are shaped by key psychosocial concepts such as hope, social support, and rely on good self-efficacy which is influenced by both clinical staff and external support.

\section{Introduction}

Each year around 110,000 people in England are affected by a stroke [1], meaning stroke affects between 176-216/100000 of the United Kingdom (UK) population [2] and around 80,000 are admitted to a hospital [3]. Approximately a third of individuals who experience a stroke will die within 3 months [4]. In the UK, stroke is the largest single cause of disability [5] with an annual cost to society of approximately $£ 8.9$ billion, around half of this cost representing direct care of the patient [6]. Experiencing a stroke and its aftermath can be devastating for patients and their families and may be associated with physical, social, and psychological consequences. Rehabilitation offers a chance for an individual to recover and/or adapt to their situation following a stroke [7]. It is essential that researchers understand the experience of stroke survivor's during rehabilitation and understand the patient's psychosocial needs. The value of qualitative research for this purpose and for informing policy and practice within healthcare is increasingly being recognised [8-11]. A particular value of synthesising qualitative data is found in examining the patient experiences of illness and their subjective beliefs $[7,8,12,13]$.

Patient experience identified through qualitative research has highlighted a need to focus on distinct areas of health care provision, including understanding respect, equality, access, and information to services, safety, choice, shared decision making, support, and representation [15-19]. Despite this call and focus there has been a lack of emphasis on the patient experience, a problem that has been recently acknowledged $[1,20]$. The current emphasis on measuring important health related outcomes utilising standardised and predetermined questions (e.g., quality of life, satisfaction surveys) is often set to the health care professional's agenda. Such outcomes may not be valued by patients or carers [21-23] or worse it may prevent a health care professional listening to or valuing 
TABLE 1: The database search terms.

\begin{tabular}{llll}
\hline Condition & Specific person & intervention & Result of intervention \\
\hline Stroke & Patient* & Rehabilitation & Experience \\
CVA & Service user & Rehab* $^{*}$ & Satisfaction \\
Cerebrovascular accident & Stroke survivor & Therapy & Well-being \\
& Client $^{*}$ & Physical therapy* & Perception \\
& & Physiotherapy & Contentedness \\
& & & Quality of therapy \\
& & & Quality of rehabilitation \\
\hline
\end{tabular}

Note: during the search each term within the column was combined using the term "OR" then the results from each column were combined using the term "AND."

*A process in searches where the words were reduced in size to capture ali variants of the word. E.gv patient* could be patient, patients, patient's, patients'.

the individual's personal experience [24]. Further to this, at present there is no guidance as to how to take into account the personal experience of the individual $[25,26]$. For instance the ICF system attempts to encompass the social functioning of the individual but does not focus on an individual's subjective experiences within healthcare [27]. For this reason there is increasing recognition that a better understanding of the patient's experiences is needed. This will help transform services helping them to achieve higher quality, in a safer environment and with more efficient processes [28-30].

A stroke can negatively influence an individual's sense of self, including one's ability to reflect upon the illness, make positive adjustments, taking control, and accepting any disabilities [31-33] and such an influence can last years after the stroke [34]. In addition to this, an individual's perception of their world can be changed challenging their relationships and social roles with others $[32,35]$. For instance the stroke can remove their professional identity and other significant identities (e.g., athletic identities) by affecting the ability to engage in activities that previously were enjoyed [36].

The psychosocial components of rehabilitation, such as expectation, sense of identity, and acceptance are important psychological concepts which are often recognised as "unmet needs" [37-41]. These form a crucial part of a stroke survivor's experience. It is important that clinicians' are able to consider how the concept of identity and other psychological concepts can be used to inform the development of care and satisfaction for the patient. One way of achieving this would be through reviewing the existing literature in a way that focuses on and values the individual's experience.

In recent years a range of different methods for synthesising qualitative research have developed [42-44]. These different methods are evident in the literature [24, 40, 45] considering individuals who have experienced a stroke. However, this previous research has not considered how an individual's identity can be influenced by their interaction and integration with the social world or how psychosocial concepts may impact on this experience as the patient transitions through rehabilitation. A metaethnography represents one way to achieve this because the process has become an effective way of interpreting the findings of multiple studies in the search of new theories or concepts $[13,44,46,47]$.
Aim. The aim of this metaethnography review was to consider how a patient's experience of stroke rehabilitation influences and evolves their identity and to consider the different psychosocial concepts and interactions that may influence this.

\section{Methods}

We followed the traditional series of seven phases from conception of an idea through to the expression of the synthesis [57]. Within the paper we illustrate these phases within three stages [58]. These stages included (1) systematic search, (2) critical appraisal, and (3) synthesis. Each stage is detailed below.

2.1. Stage 1: Systematic Search. A multipronged approach was used as recommended by Campbell et al. [47]. The following electronic databases were searched from January 2000 until October 2012: AMED, CINAHL Plus, Medline (revised), EMBASE, ASSIA, IBSS, Biological Nursing Index, ProQuest Nursing \& Allied Health Source, Social Sciences Abstracts, Sociological Abstracts, Science Citation Index, and Social sciences citation Index. The search terms can be observed in Table 1. Hand-searching of included article's reference lists was employed and where possible authors were contacted when a study could not be located.

Figure 1 provides the combined database results within a Preferred Reporting Items for Systematic Reviews and Metaanalyses (PRISMA) flow diagram [14].

\subsubsection{Eligibility Criteria. Studies were included if they}

(i) reported on patients' experience of rehabilitation after stroke following the year 2000. This date represents a major policy [59] shift towards patient-centred care within the NHS;

(ii) utilised empirical qualitative data from primary research source such as interviews, focus groups, or ethnographic research;

(iii) focussed on patient experiences reporting at least $50 \%$ of the result section with a focus on patients' experience and perceptions; 


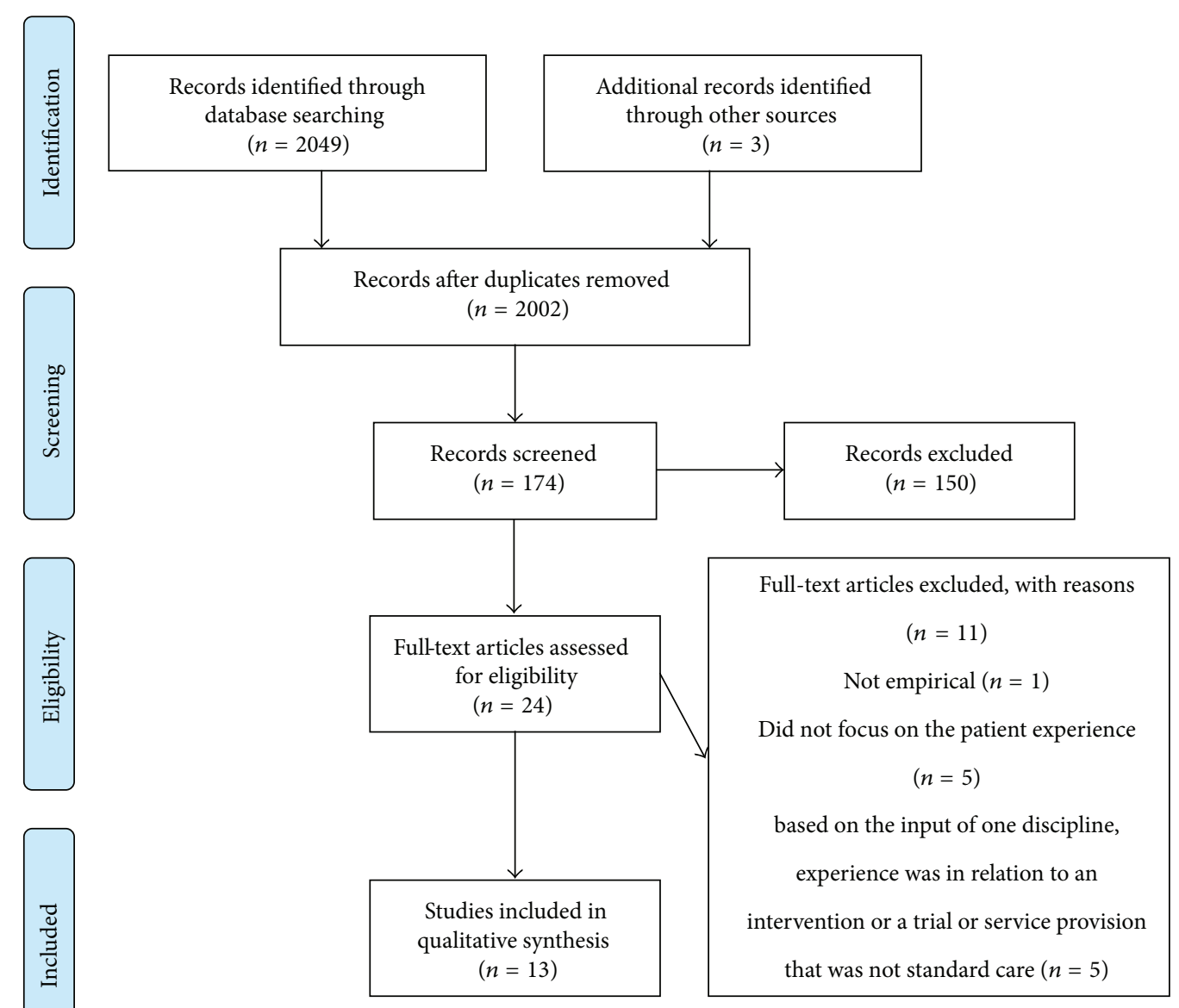

FIgURE 1: A PRISMA diagram for the study. This is based on PRISMA 2009 flow diagram and shows the search results across all four databases with numbers of articles retrieved and excluded at each stage of the selection process[14]. For more information, visit http://www.consort-statement.org/.

(iv) considered the experience of rehabilitation provided by a number of health care professionals as part of an operating stroke service;

(v) published in a peer-reviewed journal in English.

2.1.2. The Synthesis Papers. Thirteen studies met the inclusion criteria. The characteristics of the thirteen included studies are presented in Table 2. The location of the studies is shown and apart from Sabari et al. [48] carried out in the USA, the remainder were conducted within Western Europe. Five of the studies $[38,39,49,51,55]$ used a single interview to collect their primary data, one of the studies [53] used a focus group, and seven of the studies [26, 37, 48, 50, 52, 54, 56] used repeated data collection over time. All studies undertook interviews, except one, which included video analysis from within a community stroke club setting [48].

Three studies $[26,37,38]$ focused specifically on younger stroke survivors/patients (age range 37-65). Only two studies $[60,61]$ had a lower age limit of 60 years old. There were a number of topics used to guide the semistructured interviews and focus groups. Five studies [37, 39, 50-52] documented the patient's initial experiences of having the stroke, the event, and its impact.

2.2. Stage 2: Critical Appraisal and Quality Assessment. The Consolidated Criteria for Reporting Qualitative Studies [62] (COREQ) was used to assess the quality of all of the included studies. The COREQ was specifically developed to promote explicit and comprehensive interview/focus group reporting in qualitative research. It increases the reviewer's sensitivity to aspects of the research practice and identifies any flawed studies by looking for outliers in the data [10]. A scoring system was used for each item in each domain, each of the domains in the COREQ assessment tool was scored equally; for example, the details of the interviewer from domain one was given the same weighting as the theoretical framework of the study, domain two. Where an item was reported in the paper it was given a score of 1 but in the case of under reporting or where no report was given on that item the paper was given a score of 0 . Each of the items in each domain was scored and a total reported for each paper out of a possible maximum score of 32 . Table 3 provides an overview of each study's methodological score. 
TABLE 2: Characteristics of the synthesised papers.

\begin{tabular}{|c|c|c|c|}
\hline $\begin{array}{l}\text { Source } \\
\text { paper/location } \\
\text { of study }\end{array}$ & $\begin{array}{l}\text { Sample population } \\
\text { (age and gender) }\end{array}$ & $\begin{array}{l}\text { Data collection } \\
\text { and schedule }\end{array}$ & $\begin{array}{l}\text { Location of data } \\
\text { collection }\end{array}$ \\
\hline $\begin{array}{l}\text { (1) Sabari et al. } \\
\text { (2000) [48] } \\
\text { (USA) }\end{array}$ & $\begin{array}{l}\text { Aged } 45-75 \text { years } \\
6 \text { stroke survivors; } \\
5 \text { male } \\
4 \text { female carers of } \\
\text { stroke survivors }\end{array}$ & $\begin{array}{l}2 \text { Focus groups } \\
\text { (in place of } \\
\text { regular support } \\
\text { group meetings) }\end{array}$ & $\begin{array}{l}\text { Home } \\
\text { environment of } \\
\text { one of the } \\
\text { participants }\end{array}$ \\
\hline
\end{tabular}

(2) Proot et al. (2000) [49]

(Netherlands)
17 stroke patients; aged $50-85$ years; 7 female
Interview 6-11 weeks after admission to rehabilitation ward

Monthly interviews for 12 Initially hospital months maximum post-stroke

Interviews 3, 6

(2003) [37]

(Sweden)

(5) Röding et al. (2003) [38] (Sweden)

15 stroke patients All <65 years old; 9 male

(6) Cowdell and Garrett, (2003)

[39]

(U.K)

(7) Gibbon, (2004) [51]

(U.K)

(8)

Olofsson et al. (2005) [52]

(Sweden)

(9) Morris et al. (2007) [53]

(U.K)
5 stroke patients; aged 37-54;

3 male

8 stroke patients; age unknown

15 stroke patients aged 47-84; 8 male

9 stroke patients; aged 64-83; 5 females

10 stroke patients; aged 45-81; 8 male 5 carers; aged 45-83; 3 female and 12 months after admission from stroke

Home environment

Stipulated by

Interview participants: 4 in home environment

Interview

Hospital ward

One interview environment

Interviews 1: 4 months after-stroke 2: following care at stroke centre

Home environment

A focus group (1.5 hours)
Home
Specific topic covered in study

Method of analysis

Encouraged as normal as possible discussions as per support group meetings were found to be discussions about experiences of rehab

Open ended interview questions based on autonomy which patients were assisted to define for themselves initially How they defined autonomy Changes in time on persons autonomy

Constraints and improvements to their autonomy Approach of health professionals and family to their autonomy

Informal and unstructured patient asked to tell their story

Grounded theory approach

Grounded theory approach

Grounded theory approach

Interpretative approach to create categories on analysis (grounded theory approach)

Hospital stay

Rehabilitation period Current situation

Grounded theory approach

Participant current levels of activity. Views on recreational activity prior to stroke and after-stroke

Impact of stroke Meaning of rehabilitation Key contributors Goal setting Discharge home

Patient's stay in hospital Experiences of coming home Experiences of rehabilitation Experiences of follow-up appointments

Chronological questions sequenced from the stroke event to discharge
Grounded theory approach

Latent content analysis/grounded theory approach

Grounded theory approach

Grounded theory approach 
TABLe 2: Continued.

\begin{tabular}{|c|c|c|c|c|c|}
\hline $\begin{array}{l}\text { Source } \\
\text { paper/location } \\
\text { of study }\end{array}$ & $\begin{array}{l}\text { Sample population } \\
\text { (age and gender) }\end{array}$ & $\begin{array}{l}\text { Data collection } \\
\text { and schedule }\end{array}$ & $\begin{array}{l}\text { Location of data } \\
\text { collection }\end{array}$ & Specific topic covered in study & $\begin{array}{l}\text { Method of } \\
\text { analysis }\end{array}$ \\
\hline $\begin{array}{l}\text { (10) } \\
\text { Mangset et al. } \\
\text { (2008) [54] } \\
\text { (Norway) }\end{array}$ & $\begin{array}{l}12 \text { stroke patients; } \\
\text { aged } 60-87 \text { yrs; } \\
7 \text { female }\end{array}$ & $\begin{array}{l}\text { Interviews } \\
\text { (1-6 weeks after } \\
\text { admission; } 3 \\
\text { months later) }\end{array}$ & $\begin{array}{l}\text { Initially hospital } \\
\text { setting followed } \\
\text { by home } \\
\text { environment }\end{array}$ & $\begin{array}{l}\text { Share experiences in } \\
\text { connection with the stroke } \\
\text { incident } \\
\text { Experiences of being a stroke } \\
\text { patient } \\
\text { Experience of the health } \\
\text { service } \\
\text { Experience of the } \\
\text { rehabilitation process }\end{array}$ & $\begin{array}{l}\text { Grounded } \\
\text { theory approach }\end{array}$ \\
\hline $\begin{array}{l}\text { (11) } \\
\text { Ellis-Hill et al. } \\
\text { (2009) [55] } \\
\text { (U.K) }\end{array}$ & $\begin{array}{l}20 \text { stroke patients } \\
13 \text { carers }\end{array}$ & $\begin{array}{l}\text { Interview within } \\
\text { a month of } \\
\text { discharge }\end{array}$ & $\begin{array}{l}\text { Home } \\
\text { environment }\end{array}$ & $\begin{array}{l}\text { Talk about the effects of their } \\
\text { stroke } \\
\text { Their priorities for recovery } \\
\text { Their views about therapy and } \\
\text { services }\end{array}$ & $\begin{array}{l}\text { Framework } \\
\text { analysis with the } \\
\text { grounded } \\
\text { theory approach }\end{array}$ \\
\hline $\begin{array}{l}(12) \\
\text { Erikson et al. } \\
\text { (2010) [26] } \\
\text { (Sweden) }\end{array}$ & $\begin{array}{l}9 \text { stroke survivors; } \\
\text { Aged } 42-61 \text { years; } \\
6 \text { male }\end{array}$ & $\begin{array}{l}\text { Interviews }(1,3, \\
6 \text { and } 12 \\
\text { months) }\end{array}$ & $\begin{array}{l}\text { At } 1 \text { month: } \\
\text { hospital setting } \\
\text { At } 3,6 \text {, and } 12 \\
\text { months: } \\
\text { outpatient clinic }\end{array}$ & $\begin{array}{l}\text { Experiences performing daily } \\
\text { activities relative to those } \\
\text { experiences prior to acquiring } \\
\text { a stroke } \\
\text { Experiences of daily life with } \\
\text { stroke }\end{array}$ & $\begin{array}{l}\text { Grounded } \\
\text { theory approach }\end{array}$ \\
\hline $\begin{array}{l}(13) \\
\text { Wottrich et al. } \\
(2012)[56] \\
\text { (Sweden) }\end{array}$ & $\begin{array}{l}5 \text { stroke patients; } \\
\text { aged } 44-70 \text { years; } \\
3 \text { female }\end{array}$ & $\begin{array}{l}\text { Interviews } \\
\text { 1: } 1-7 \text { days prior } \\
\text { to discharge } \\
2: 13-30 \text { days } \\
\text { after discharge } \\
\text { 3: } 3-4 \text { months } \\
\text { after discharge }\end{array}$ & $\begin{array}{l}\text { Interview 1: } \\
\text { hospital setting } \\
\text { Interviews } 2 \text { and } \\
\text { 3: home } \\
\text { environment }\end{array}$ & $\begin{array}{l}\text { Experience of ending contact } \\
\text { with staff on the ward } \\
\text { Experience of being } \\
\text { discharged and coming home } \\
\text { and of being at home } \\
\text { Experience of everyday life } \\
\text { today } \\
\text { Strategies for handling a } \\
\text { changed everyday } \\
\text { situation/life situation } \\
\text { Conceptions about one's } \\
\text { future everyday situation/life } \\
\text { situation } \\
\text { Experience of important } \\
\text { aspects that help or hinder } \\
\text { progress in adapting to a } \\
\text { changed everyday } \\
\text { situation/life situation }\end{array}$ & $\begin{array}{l}\text { Grounded } \\
\text { theory approach }\end{array}$ \\
\hline
\end{tabular}

No studies were fatally flawed [10] and all thirteen studies were included in the synthesis. Items were consistently reported as poor within domain one (research team and reflexivity) which included a description of the interviewer's relationship to the participant and the interviewer's characteristics. This finding was not considered sufficient to warrant further consideration within our analysis $[10,47,58]$.

2.3. Stage 3: The Synthesis. During this phase 3 levels (1st, $2 \mathrm{nd}$, and 3rd order) of interpretations were made [57, 58, 63]. The interpretations clarify the source of the information and encourage an in depth understanding of the original data in order to begin to form constructs $[60,63,64]$. The thirteen papers were examined in chronological order and two tables illustrating the first and second order interpretations were constructed keeping the findings separate (these findings are available from the primary author). In each table a separate column was used for notes. The supervising author (XX) assisted with the verification of interpretations made, recording techniques used, and development of third order interpretations. Key metaphors and concepts from the studies were juxtaposed to establish any relationship between the data [57]. To achieve this, the interpretation tables were used and the papers analysed chronologically to form an interpretation grid. Both the tables and grid are available from the primary author. The grid was filled analysing each paper in a separate row and each column represented a second order construct.

The included studies were amenable to reciprocal translation, as they all related to similar concepts and experiences [57]. Using the interpretation grid the concepts of the original studies were brought together, interpretations were made 
TABLE 3: The summary of results of the COREQ (Tong et al., 2007 [62]) appraisal for the thirteen included studies.

\begin{tabular}{|c|c|c|c|c|}
\hline Author/year of publication & $\begin{array}{c}\text { Domain } 1(8) \\
\text { Research team and reflexivity }\end{array}$ & $\begin{array}{l}\text { Domain } 2(15) \\
\text { Study design }\end{array}$ & $\begin{array}{l}\text { Domain } 3(9) \\
\text { Analysis and findings }\end{array}$ & Total (32) \\
\hline Sabari et al. (2000) [48] & 6 & 13 & 8 & 27 \\
\hline Proot et al. (2000) [49] & 3 & 11 & 8 & 22 \\
\hline Burton (2000) [50] & 4 & 12 & 6 & 22 \\
\hline Bendz (2003) [37] & 5 & 10 & 7 & 22 \\
\hline Röding et al. (2003) [38] & 3 & 10 & 8 & 21 \\
\hline Cowdell and Garrett (2003) [39] & 6 & 11 & 6 & 23 \\
\hline Gibbon (2004) [51] & 5 & 11 & 6 & 22 \\
\hline Olofsson et al. (2005) [52] & 4 & 12 & 6 & 22 \\
\hline Morris et al. (2007) [53] & 6 & 11 & 8 & 25 \\
\hline Mangset et al. (2008) [54] & 3 & 12 & 6 & 21 \\
\hline Ellis-Hill et al. (2009) [55] & 6 & 12 & 7 & 25 \\
\hline Erikson et al. (2010) [26] & 6 & 12 & 6 & 24 \\
\hline Wottrich et al. (2012) [56] & 5 & 10 & 7 & 22 \\
\hline Mean & 4.8 & 11.3 & 6.9 & 22.9 \\
\hline Median & 5 & 11 & 7 & 22 \\
\hline Mode & 6 & 12 & 6 & 22 \\
\hline
\end{tabular}

by the author as to where similarities in the data were, and key themes and subthemes were created. An attempt was made to retain the language used by the papers whilst creating new metaphors in the analysis [61]. Once translated the data was assessed for themes that followed a line of argument. A "line of argument synthesis" is defined as a new model, theory, or understanding from the synthesis of data using metaethnography [64]. This was developed by the supervising author utilising previous theoretical constructs, including the paradox of chronic illness [13] and the evolution of an individual's identity [46].

\section{Findings}

Two key themes were identified: the evolution of identity and the psychosocial constructs that influence experience. Each theme contains subthemes translated from the interpretation grid. Table 4 that follows shows the thematic breakdown.

\subsection{Theme 1: The Evolution of Identity}

3.1.1. Subtheme 1a: Sense of the Individual's Identity. A sense of the individual encompasses the whole person, their individual factors such as age and comorbidities and the activities and hobbies of their previous life. Participants suggested their broader human needs were not met and that they were not acknowledged as individuals in the rehabilitation experience $[53,54]$. A more recent concept in some of the studies, the "individual recovery model," is considered a direct response to this and an opportunity for professionals to understand how stroke survivors see a way to their recovery $[55,56]$. The model suggests that an individual combines knowledge of themselves and their life experience with professional opinions and advice to create a path and understanding for their own recovery. Essentially this concept is not a new one; all the synthesised studies had the needs and wishes of the individual as key to successful and satisfying experience within rehabilitation. Indeed, many of the older studies also acknowledged that individuals had their own ideas of recovery and rehabilitation [37, 39, 48, 53]. These wishes are clearly associated with their hopes and expectations. For instance, a participant in the study by Bendz [37] states " $I$ want to get back to my usual self...the one I used to be." (Female, 64 years, after 3 months).

3.1.2. Subtheme $1 b$ : Being at the Dividing Line. This subtheme considers a key aspect of adjustment for individuals who have experienced a stroke, when they acknowledge the meaning of the stroke in their lives. This subtheme occurs in the patient reported experience at times of transition when self-realisation (acknowledgment and understanding of one's present situation) is heightened due to exposure to a new reality, such as going home after rehabilitation, when adjustments and new insights are required [52]. Transition, adjustment and the learning associated with these experiences appear to be significant for the individual in the rehabilitation process. By being able to problem solve and practice tasks, selfesteem and confidence are improved [56], as is self-efficacy. Expectations are high for individuals at the time of transition where the adjustments that follow require recognition of the "new" self. The role of the professional and the family seems crucial at this time (see Table 3) to assist the individual to rebuild and restructure their world through this experience [51].

3.1.3. Subtheme 1c: Rebuilding, Restructuring, and Identity. Within this subtheme individuals acknowledge the situation that their stroke caused and consider the future and begin 
TABLE 4: Findings of the synthesised translations.

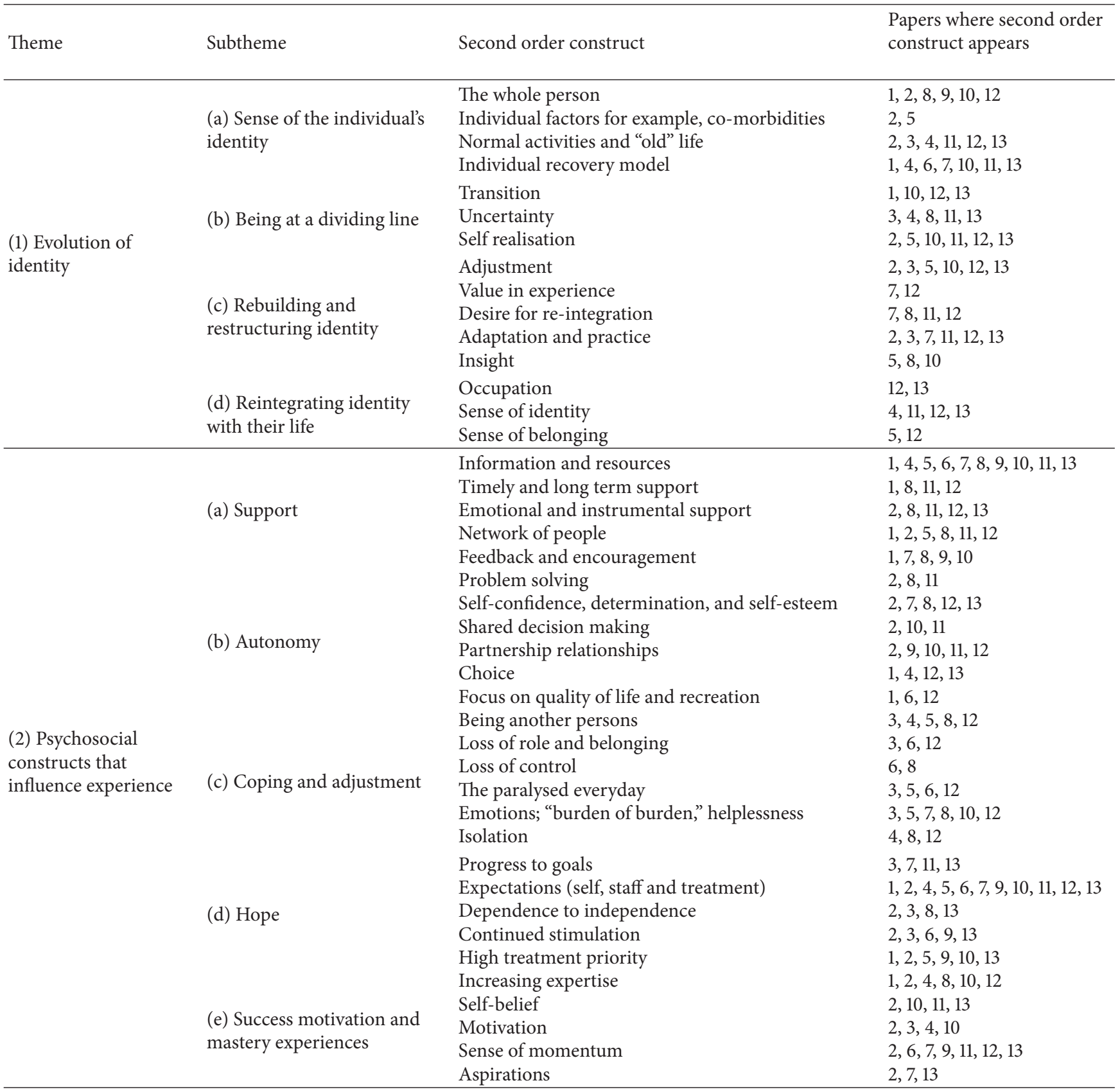

Note: 1: Sabari et al., 2000 [48], 2: Proot et al., 2000 [49], 3: Burton, 2000 [50], 4: Bendz, 2003 [37], 5: Röding et al., 2003 [38], 6: Cowdell and Garrett, 2003 [39], 7: Gibbon, 2004 [51], 8: Olofsson et al., 2005 [52], 9: Morris et al., 2007 [53], 10: Mangset et al., 2008 [54], 11: Ellis-Hill et al., 2009 [55], 12 : Erikson et al., 2010 [26], and 13: Wottrich et al., 2012 [56].

a process of adaptation and practice. Individuals with a stroke reported getting to a point following the acknowledgement of their situation, during or following rehabilitation where they consider the role and meaning of what their life will be. Individuals require time to adjust to this realisation $[38,49,50,54]$. They utilise experiences $[26,51]$ to acquire this understanding and begin to attempt adaption to their stroke through practice. The desire for reintegration with aspects of their identity that can be restored is undertaken. This desire is an important motivating force. For instance,
Erikson et al. [26] highlighted a participant at 12 months after stroke who stated "Your goal is to live a normal life, just as it used to be. Your children should not need to think that it is an awkward old man that they are walking together with. You do not want to deviate more than before. It's important for oneself too" (page, 836).

3.1.4. Subtheme 1d: Reintegrating Identity with Their Life. Individuals' desire for reintegration to their social world after stroke was found to inspire engagement in rehabilitation 
and gave the feeling of increased energy and meaning in an individual's life $[39,50]$. Individuals did not talk about their experience of participation but of belonging, having a sense of identity and an occupation $[26,38]$. It appears that more than lacking in participation, stroke survivors described experiencing a lack of meaning to the tasks they practised in recreation and therapy $[39,55]$. There was a great value to feeling a sense of belonging during the process of change that occurs with rehabilitation. The concept of belonging and acceptance of a "new" self appears important in the participant's experience of rehabilitation after a stroke. It is enhanced with occupation and success in activities of daily living by improving self-esteem and confidence [52].

\subsection{Theme 2: Psychosocial Constructs That Influence Experience}

3.2.1. Subtheme $2 a$ : Social Support. The partnerships and support experienced varied between studies and was provided by a network of people. The variability was probably due to the studies representing a cross-section of international data from acute rehabilitation, to, services for chronic stroke survivors. Support from professional staff and the individual's network of friends and family took on many forms. It included instrumental and emotional support as well as access to timely but potentially long term services providing information and resources. Frequently the participants highlighted the positive experience of having skilled staff available to provide feedback and encouragement $[48,52,53$, 55]. Further, the different ways that participants experienced support within their rehabilitation affected their ability to regain autonomy and reconcile their sense of self. Erikson et al., illustrate the vulnerability of a patient: "I become very uncertain even though I know I'm right. My feeling is that the staff think that I understand less than I actually do" (page 833).

3.2.2. Subtheme 2b: Autonomy. In the majority of studies autonomy was highlighted as a key factor that influenced outcome by the majority (11/13) of studies. Individuals recognised having autonomy helped to build self-esteem and confidence instead of traditional paternalistic models of care constraining their independence and self-determination [49]. The ability to make their own choices and solve their own problems led to participants taking increased responsibility and improving their outcomes [52]. Participants identified that partnerships with professional staff and shared decision making improved their experience [54]. So through gaining autonomy participants were better able to reconcile their sense of "self" and this acted as a primary way to move on from the current self towards evolving the self.

3.2.3. Subtheme 2c: Coping and Adjustment. Adjusting to and managing the effects of the stroke were expressed in several ways. Individuals were both able to look forward to the future and identify an ability to cope. Burton [50] suggests that "when new coping mechanisms had been established and were perceived to be successful, informants felt more able to do things" (page, 305). Other patients needed to express multiple losses. Patients described a loss of role, loss of belonging, loss of control, and the loss of ability described as the "paralysed everyday" [38, 39]. Patients described dependency on others and feelings of helplessness, further to this, the burden of being a burden (the negative thoughts and feelings associated with being a burden on someone else) and isolation [37, 51]. Indeed, six studies $[26,38,50-52,54]$ identified that patients did not want to be a burden on family members or friends. This perception clearly affected an individual's ability to cope. Although, the concept of "burden of burden" and its impact on well-being requires further investigation [26].

3.2.4. Subtheme $2 d$ : Hope. Hope, described by participants in respect of what they wished to happen and their expectations, involved a sense of moving forward continuously from dependence to independence similar to that described by coping [49]. The participant's expectations of training and the role that professionals had in their rehabilitation was high and observed specifically when describing their disappointment in the therapy input on going home or reduced opportunities for recreation $[39,55]$. Many of the studies contained first order constructs of hope by the participants and the concept of hopelessness when finding themselves not progressing in their own environments [53]. Bendz [37] followed participants up to a year after stroke and found that participants did not want to give up hope: "I'm going to train... feel that you mustn't give up...I do it to be able to...carry on existing...no good giving up...oh no." (page, 219). Similar expressions from Wottrich et al. [56] illustrated that the need for a concrete hope a patient has: "My hope is to recover to my previous level, to be able to walk as well as before and to use the arm, to get as close as possible to where I was before, preferably all the way there. I'm not sure it's going to be possible, it's just training" (page, 1220).

3.2.5. Subtheme 2e: Success, Motivation, and Mastery Experiences. How participants perceived their success was dependent on what they had experienced moving forward and whether they were in a positive emotional state. The second order constructs of self belief and aspirations were enhanced when participants were achieving success [56]. Many studies reported participants experiencing a sense of momentum to recovery over time where the experience of some successful recovery helped to maintain their motivation [53-55]. Staff could be central to this, as Gibbon [51] illustrates " $M y$ faith was in (named nurse)... he always made you get on and found ways to encourage you; he always lifted my spirits" (page, 10).

3.2.6. The Line of Argument Synthesis. Our synthesis of themes and subthemes clearly identifies a need for health care professionals to consider their interaction and care giving around the psychosocial needs of the patient in order to support their transition in identity. These needs are directly associated with the challenge the participant has in coming to terms with an altered identity. Figure 2 provides details of the processes involved when the stroke influences a patient's identity. 


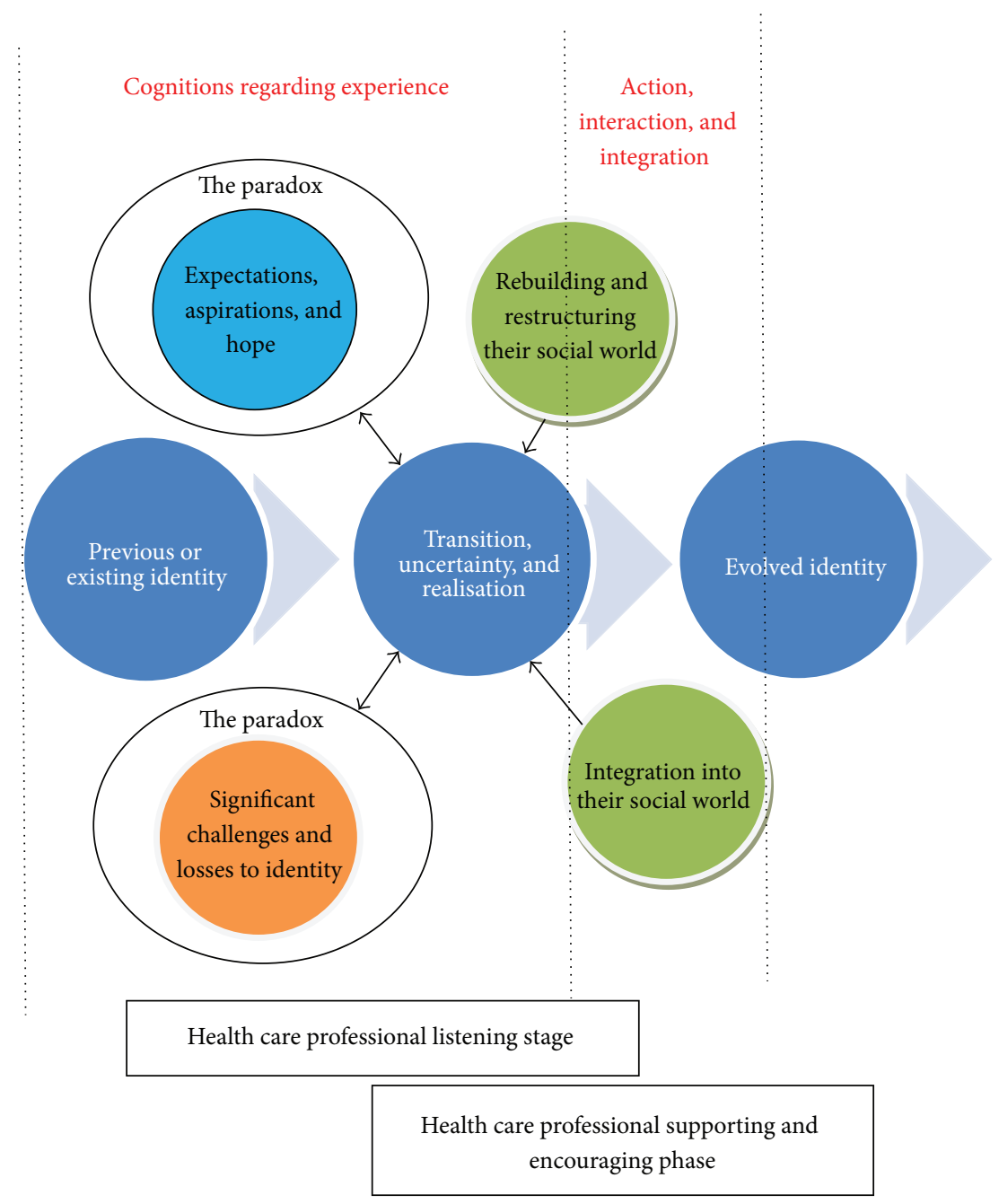

FIGURE 2: The model of transitional experiences within stroke rehabilitation.

The model of transitional experiences within stroke rehabilitation illustrates the transition in identity and factors which impact on that transition. Aligned with previous research in stroke and other neurological conditions [13] we utilise the paradox of chronic illness [65] to highlight that individuals are impelled to defy limitations imposed by their stroke but also concurrently have some understanding and acceptance of their limitations. Further to this, what an individual can accept about their situation and illness varies (inter-patient variation) and health care professional need to consider what a patient can accept.

Importantly for the health care professional, the model generated from this synthesis illustrates the need and value of considering the process of transition in identity and the importance of listening when there is uncertainty, expression of losses, or when an individual's expresses hope and aspirations. There is value in exploring such expressions to communicate to the patient that they have been heard and valued as an individual and, following this, attempting to change or help an individual that it is done in a style that uses questions to offer different or alternative views and possibilities (emphasis on negotiation with the patient) rather than confronting a patient and demanding change (emphasis on directing the patient). This is important because of the difficulty in or time needed when adapting to a new identity. Further, health care professions are vital in encouraging and supporting the individual when they attempt to integrate themself into their life following rehabilitation, as at these times, they may be most able to positively alter, adapt, and evolve their identity. Support and encouragement needs to reflect the use of psychosocial concepts which are identified within the respective theme.

\section{Discussion}

The current metaethnography has been able to consider how an individual's identity evolves and is influenced during stroke rehabilitation. We identified two themes which recognised that the individuals' identity is an essential aspect of perceived recovery and as such a central need that requires attention by clinicians and researchers alike. It is well known 
that individuals experience a process of reconstitution of self in response to the burden of living with chronic illness. Individuals actively engage by reflecting on their illness which helps them make sense of who they are, experiencing self in a newly conscious way [66-68]. Restoring a sense of control and self-sufficiency so an individual that feels able to rebuild and integrate their life is essential to moving on following a stroke. In this study several psychosocial constructs can be considered as factors which are influenced by the interaction with health care professionals. Within this discussion we focus on three specific constructs including social support, master experiences, and aspects that relate to self-efficacy and an individual's hope.

All the current studies except one [50] illustrated the importance of at least one dimension of social support. The four different dimensions [69] include emotional, esteem, information, and tangible; health care professionals may consider the need to match support to the situation a patient is in [69]. For instance, within uncontrollable situations for example, following diagnosis, emotional support may be best; however, once a patient perceives a more controllable situation, informational and tangible support may be best. Further the timing of support [70] illustrates different needs alongside different stressful situations [71] (Crisis, transition, and deficit (Crisis is defined as a situation that is severely threatening to ones well-being and incites emotional arousal, sudden onset, and limited duration. Transition is defined as a period of change in an individual's relationships or assumptive world. Deficit is a situation where one's life has chronically excessive demands.)). During crisis, emotional support can be provided, during transition, information support may be more appropriate, and during a deficit, tangible support could be provided.

Both instrumental and emotional support can influence the transitional model of stroke care model via improved autonomy. When external support is provided the transition to a reintegrated identity is more rapid and extensive [72]. Increased family support also results in patients being more informed and satisfied with the quantity of information and education provided $[21,73,74]$. Support positively impacts on autonomy and therefore self-esteem and well-being by preserving positive characteristics and attitude towards rehabilitation outcomes. In the absence of external support, which could be provided by recreation or employment, an individual may have a decreased sense of self-perception in conjunction with a decreased sense of belonging [26]. In order to experience the valuable sense of belonging high levels of self-efficacy are required to change behaviour and learn from social situations.

Key dimensions of an individual's self efficacy were identified within the current studies including the need for verbal persuasion in the form of encouragement and feedback from health care professionals [48, 51-54] and mastery experiences, in the form of a sense of momentum $[26,39,49,51,53,55,56]$, increasing expertise $[26,37,48,49$, $52,54]$, and progress to goals $[50,51,55,56]$. An individual's self-efficacy affects their ability to learn, improves their level of achievement, and determines their motivation [73, 75-77]. According to the social cognitive theory a high self-efficacy helps individuals to persevere, despite difficulties, to achieve the things they value which positively influences their health and well-being [75, 78]. The subdomains of self-efficacy require further consideration. (1) Mastery experiences are the most effective force in creating personal efficacy. Individuals with stroke require time to practice and reflect on performing functional abilities well [73, 76, 79]. Repeated failures can reduce self-efficacy. (2) Verbal encouragement and supportive comments to progress towards goals are essential. Although it often does not instil strong self-belief and can have a negative effect in a challenging environment [35] or can be affected by the sources credibility and expertise [76]. (3) Vicarious experience or modelling the behaviour of others can help induce a feeling that they can posses the capability to master comparable activities [35]. This highlights the need to consider the participant's experience within a rehabilitation setting. (4) Performing functional tasks creates physiological feedback for the participant. It is important that patients interpret such experience as positive, rather than negative. For instance walking more independently [80].

A number of studies in this synthesis included interpretations of data from participants discussing feelings of despondency or anxiety during the rehabilitation process $[49,50,53-55]$. This may be as a result of an individual having poor self-efficacy often associated with feeling a lack of control of one's situation. An inability to influence events may result in self-isolation and feelings of futility causing a decrease in confidence and an increasing restriction of social roles [81]. This may also be associated with the potential for a negative cycle when one's situation can be perceived as worsening.

Individuals in all studies recognised different psychological concepts and cognitions that directly related to hope. Factors that influenced hope included a focus on the progress towards goals $[50,51,55,56]$, the need to gain independence $[49,50,52,56]$, and finally in all studies except two [50, 52] the expectation in one's self. The model illustrates that patients' hopes are likely to be dependent on their previous identity and perceived losses. In accordance with the paradox of chronic illness [13], it is important to understand what an individual can accept about the loss they perceive and how it affects their identity. Further to this, it is important to recognise that in some instances the hope of a possible recovery may be an individual's main agency for motivation and challenging the effects of the stroke. Removing this hope for change can leave a patient with a very negative view of the therapist [82]. Rebuilding and restructuring one's identity relies on mastery of experiences, learning and self-development, where hope changes and adapts due to perceived success and being under the influence of others.

4.1. Clinical Implications. Several implications for health care professionals in clinical practice can be identified from the current results including a need to

(1) be aware that an individual's previous identity will impact on how they adjust to their life with a stroke;

(2) consider the importance of social support behaviours when a patient is adjusting to their stroke. Specifically 
understanding how to support an individual's confidence, autonomy towards rehabilitation activities, hope, and expectations;

(3) understand the importance of self-efficacy subdomains;

(4) understand that once established self-efficacy can generalise to other situations where these new perspectives can lead to changes in behaviour resulting in better overall health and function.

4.2. Limitations. All the synthesised studies had their own inclusion criteria for the focus groups or interviews and all primary data was collected from stroke survivors who did not suffer from any severe cognitive or language difficulties. This does bias the findings of the study in favour of survivors in the less severe stroke category decreasing the generalisability of the findings. Another limitation of this study was that the rehabilitation experience data was not relevant to a specific healthcare system or rehabilitation style, but in the majority reflected a European rehabilitation experience. In this review the findings have therefore been of a more general nature but this may reduce the study's usefulness for specific service development in a specific healthcare system. The line of argument synthesis was influenced by the supervising author's a priori analysis.

4.3. Clinical Implications. Patient experience is linked to quality of life measures such as well-being and is often dependent on an individual's sense of engagement with the healthcare system [23]. In this study positive experiences appear to be associated with an improved ability for participants to manage their condition and make positive health and well-being choices, highlighting the importance of subjective experiences. Rehabilitation occurs in the hospital setting, the home environment, and the local community where outcome measures form an essential part of the process both at the individual level of effective improvement and at service level in justification for continued input. In order to assess the effectiveness of rehabilitation on the subjective experiences highlighted in this model, increased emphasis on outcome measurement would be required.

\section{Conclusion}

The metaethnography synthesised and translated constructs from thirteen studies producing two themes and a model relating to the transitional experiences within rehabilitation. It is important to acknowledge the complexity and the multidimensional nature of the recovery process for stroke survivors. In this context designing interventions to facilitate recovery is not a simple matter. This model of transitional patient experience may be useful when considering the importance of valuing an individual. It may have educational value for professionals not used to prioritising patient experience and subjective beliefs in the rehabilitation process.

\section{Conflict of Interests}

The authors declare that there is no conflict of interests regarding the publication of this paper.

\section{Acknowledgment}

The authors would like to acknowledge Dr. Fiona Jones for critique provided to early drafts.

\section{References}

[1] Excellence NIfHaC, Stroke Rehabilitation. Long-Term Rehabilitation after Stroke, National Institute for Health and Care Excellence, London, UK, 2013.

[2] Physicians RCo, Ed., National Clinical Guideline for Stroke, Royal College of Physicians, London, UK, 2008.

[3] Commission CQ, Supporting Life after Stroke, Care Quality Commission, London, UK, 2011.

[4] Office NA, Reducing Brain Damage: Faster Access to Better Stroke Care, National Audit Office, London, UK, 2005.

[5] Organisation WH, Atlas of Heart Disease and Stroke, World Health Organisation, Geneva, Switzerland, 2004.

[6] Ö. Saka, A. Mcguire, and C. Wolfe, "Cost of stroke in the United Kingdom," Age and Ageing, vol. 38, no. 1, pp. 27-32, 2009.

[7] E. A. G. Joosten, L. DeFuentes-Merillas, G. H. de Weert, T. Sensky, C. P. F. van der Staak, and C. A. J. de Jong, "Systematic review of the effects of shared decision-making on patient satisfaction, treatment adherence and health status," Psychotherapy and Psychosomatics, vol. 77, no. 4, pp. 219-226, 2008.

[8] R. Campbell, P. Pound, C. Pope et al., "Evaluating metaethnography: a synthesis of qualitative research on lay experiences of diabetes and diabetes care," Social Science \& Medicine, vol. 56, no. 4, pp. 671-684, 2003.

[9] N. Mays, C. Pope, and J. Popay, "Systematically reviewing qualitative and quantitative evidence to inform management and policy-making in the health field," Journal of Health Services Research and Policy, vol. 10, no. 1, pp. 6-20, 2005.

[10] M. Dixon-Woods, A. Sutton, R. Shaw et al., "Appraising qualitative research for inclusion in systematic reviews: a quantitative and qualitative comparison of three methods," Journal of Health Services Research and Policy, vol. 12, no. 1, pp. 42-47, 2007.

[11] Dissemination CfRa, Systematic Reviews. CRD'S Guidance for Undertaking Reviews in Health Care York, Centre for Reviews and Dissemination, 2008.

[12] C. McKevitt, J. Redfern, F. Mold, and C. Wolfe, "Qualitative studies of stroke: a systematic review," Stroke, vol. 35, no. 6, pp. 1499-1505, 2004.

[13] A. Soundy, B. Smith, H. Dawes, H. Pall, K. Gimbrere, and J. Ramsay, "Patient's expression of hope and illness narratives in three neurological conditions: a meta-ethnography," Health Psychology Review, vol. 7, no. 2, pp. 177-201, 2013.

[14] D. Moher, A. Liberati, J. Tetzlaff, and D. G. Altman, "Preferred reporting items for systematic reviews and meta-analyses: the PRISMA statement," BMJ, vol. 339, Article ID b2535, 2009.

[15] A. Darzi, "High quality care for all: NHS next stage review final report," Tech. Rep., Department of Health, London, UK, 2008.

[16] Health Do., "High quality care for all: our journey so far," Tech. Rep., Department of Health, London, UK, 2009.

[17] Health Do., “The NHS constitution for England," Tech. Rep., Department of Health, London, UK, 2010. 
[18] Health Do., "Equity and excellence: liberating the NHS," Tech. Rep., London, UK, 2011.

[19] C. Williamson, Towards the Emancipation of Patients. Patient's Experiences and the Patient Movement, Policy Press, Bristol, UK, 2010.

[20] R. Francis, "Report of the Mid Staffordshire NHS foundation trust public inquiry," Tech. Rep., Staffordshire NHS Foundation Trust, 2013.

[21] P. Pound, K. Tilling, A. G. Rudd, and C. D. A. Wolfe, "Does patient satisfaction reflect differences in care received after stroke?" Stroke, vol. 30, no. 1, pp. 49-55, 1999.

[22] G. Dowswell, T. Dowswell, J. Lawler, J. Green, and J. Young, "Patients' and caregivers' expectations and experiences of a physiotherapy intervention 1 year following stroke: a qualitative study," Journal of Evaluation in Clinical Practice, vol. 8, no. 3, pp. 361-365, 2002.

[23] S. H. Staniszewska and L. Henderson, "Patients' evaluations of the quality of care: influencing factors and the importance of engagement," Journal of Advanced Nursing, vol. 49, no. 5, pp. 530-537, 2005.

[24] K. Salter, C. Hellings, N. Foley, and R. Teasell, “The experience of living with stroke: a qualitative meta-synthesis," Journal of Rehabilitation Medicine, vol. 40, no. 8, pp. 595-602, 2008.

[25] A. Häggström and M. L. Lund, "The complexity of participation in daily life: a qualitative study of the experiences of persons with acquired brain injury," Journal of Rehabilitation Medicine, vol. 40, pp. 89-95, 2008.

[26] A. Erikson, M. Park, and K. Tham, "Belonging: a qualitative, longitudinal study of what matters for persons after stroke during one year of rehabilitation," Journal of Rehabilitation Medicine, vol. 42, no. 9, pp. 831-838, 2010.

[27] Organisation WH, International Classification of Functioning, Disability and Health (ICF), World Health Organisation, Geneva, Switzerland, 2013.

[28] R. Galvin, T. Cusack, and E. Stokes, "Physiotherapy after stroke in Ireland: a qualitative insight into the patients' and physiotherapists' experience," International Journal of Rehabilitation Research, vol. 32, no. 3, pp. 238-244, 2009.

[29] L. Salisbury, K. Wilkie, C. Bulley, and J. Shiels, "After the stroke': patients' and carers' experiences of healthcare after stroke in Scotland," Health and Social Care in the Community, vol. 18, no. 4, pp. 424-432, 2010.

[30] Excellence NIfHaC, Scope: Patient Experience in Adult NHS Services: Improving the Experience of Care for People Using Adult NHS Services, National Institute for Health and Clinical Excellence, London, UK, 2010.

[31] J. M. Morse and J. L. Johnson, The Illness Experience: Dimensions of Suffering, Sage, Thousand Oaks, Calif, USA, 1991.

[32] M. S. Clark, "Patient and spouse perceptions of stroke and its rehabilitation," International Journal of Rehabilitation Research, vol. 23, no. 1, pp. 19-29, 2000.

[33] C. Yuill, I. Crinson, and E. Duncan, Key Concepts in Health Studies, Sage, London, UK, 2010.

[34] C. S. Ellis-Hill, S. Payne, and C. Ward, "Self-body split: issues of identity in physical recovery following a stroke," Disability and Rehabilitation, vol. 22, no. 16, pp. 725-733, 2000.

[35] J. P. Wood, D. M. Connelly, and M. R. Maly, "Getting back to real living: a qualitative study of the process of community reintegration after stroke," Clinical Rehabilitation, vol. 24, no. 11, pp. 1045-1056, 2010.
[36] C. Haslam, A. Holme, S. A. Haslam, A. Iyer, J. Jetten, and W. H. Williams, "Maintaining group memberships: social identity continuity predicts well-being after stroke," Neuropsychological Rehabilitation, vol. 18, no. 5-6, pp. 671-691, 2008.

[37] M. Bendz, "The first year of rehabilitation after a stroke-from two perspectives," Scandinavian Journal of Caring Sciences, vol. 17, no. 3, pp. 215-222, 2003.

[38] J. Röding, B. Lindström, J. Malm, and A. Ohman, "Frustrated and invisible-younger stroke patients' experiences of the rehabilitation process," Disability and Rehabilitation, vol. 25, pp. 867-874, 2003.

[39] F. Cowdell and D. Garrett, "Recreation in stroke rehabilitation part two: exploring patients' views," International Journal of Therapy and Rehabilitation, vol. 10, pp. 456-462, 2003.

[40] H. Peoples, T. Satink, and E. Steultjens, "Stroke survivors' experiences of rehabilitation: a systematic review of qualitative studies," Scandinavian Journal of Occupational Therapy, vol. 18, no. 3, pp. 163-171, 2011.

[41] G. P. Prigatano, "The importance of the patient's subjective experience in stroke rehabilitation," Topics in Stroke Rehabilitation, vol. 18, no. 1, pp. 30-34, 2011.

[42] M. Dixon-Woods, S. Agarwal, B. Young, D. Jones, and A. Sutton, Integrative Approaches to Qualitative and Quantitative Evidence, Agency NHD, London, UK, 2004.

[43] M. Sandelowski, J. Barroso, and C. I. Voils, "Using qualitative metasummary to synthesize qualitative and quantitative descriptive findings," Research in Nursing \& Health, vol. 30, no. 1, pp. 99-111, 2007.

[44] E. Barnett-Page and J. Thomas, "Methods for the synthesis of qualitative research: a critical review," BMC Medical Research Methodology, vol. 9, no. 1, article 59, 2009.

[45] M. C. Reed, V. Wood, R. Harrington, and J. Paterson, "Developing stroke rehabilitation and community services: a metasynthesis of qualitative literature," Disability and Rehabilitation, vol. 34, no. 7, pp. 553-563, 2012.

[46] A. Soundy, T. Kingstone, and C. Coffee, "Understanding the psychosocial processes of physical activity for individuals with severe mental illness: a meta-ethnography," in Mental IllnessesEvaluation, Treatments and Implications, 2012.

[47] R. Campbell, P. Pound, M. Morgan et al., "Evaluating metaethnography: systematic analysis and synthesis of qualitative research," Health Technology Assessment, vol. 15, no. 43, pp. 1$164,2011$.

[48] J. S. Sabari, J. Meisler, and E. Silver, "Reflections upon rehabilitation by members of a community based stroke club," Disability \& Rehabilitation, vol. 22, no. 7, pp. 330-336, 2000.

[49] I. M. Proot, H. H. Abu-Saad, W. P. de Esch-Janssen, H. F. J. M. Crebolder, and R. H. J. Ter Meulen, "Patient autonomy during rehabilitation: the experiences of stroke patients in nursing homes," International Journal of Nursing Studies, vol. 37, no. 3, pp. 267-276, 2000.

[50] C. R. Burton, "Living with stroke: a phenomenological study," Journal of Advanced Nursing, vol. 32, no. 2, pp. 301-309, 2000.

[51] B. Gibbon, "Service user involvement: the impact of stroke and the meaning of rehabilitation," International Journal of Therapy and Rehabilitation, vol. 7, pp. 8-12, 2004.

[52] A. Olofsson, S.-O. Andersson, and B. Carlberg, "If only I manage to get home I'll get better'-interviews with stroke patients after emergency stay in hospital on their experiences and needs," Clinical Rehabilitation, vol. 19, no. 4, pp. 433-440, 2005. 
[53] R. Morris, O. Payne, and A. Lambert, "Patient, carer and staff experience of a hospital-based stroke service," International Journal for Quality in Health Care, vol. 19, no. 2, pp. 105-112, 2007.

[54] M. Mangset, T. E. Dahl, R. Førde, and T. B. Wyller, "We're just sick people, nothing else'....Factors contributing to elderly stroke patients' satisfaction with rehabilitation," Clinical Rehabilitation, vol. 22, no. 9, pp. 825-835, 2008.

[55] C. Ellis-Hill, J. Robison, R. Wiles, K. McPherson, D. Hyndman, and A. Ashburn, "Going home to get on with life: patients and carers experiences of being discharged from hospital following a stroke," Disability \& Rehabilitation, vol. 31, no. 2, pp. 61-72, 2009.

[56] A. Wottrich, K. Åström, and M. Löfgren, "On parallel tracks: newly home from hospital-people with stroke describe their expectations," Disability \& Rehabilitation, vol. 34, pp. 1218-1224, 2012.

[57] G. W. Noblit and R. Dwight Hare, Meta-Ethnography: Synthesising Qualitative Studies, Sage, London, UK, 1988.

[58] A. Malpass, A. Shaw, D. Sharp et al., "'Medication career' or "Moral career"? The two sides of managing antidepressants: a meta-ethnography of patients' experience of antidepressants," Social Science \& Medicine, vol. 68, no. 1, pp. 154-168, 2009.

[59] Health Do., "The NHS Plan: a plan for investment, a plan for reform," Tech. Rep., Department of Health, London, UK, 2000.

[60] A. Malpass, H. Carel, M. Ridd et al., "Transforming the perceptual situation: a meta-ethnography of qualitative work reporting patients'experiences of mindfulness-based approaches," Mindfulness, vol. 3, pp. 60-75, 2012.

[61] L. H. Doyle, "Synthesis through meta-ethnography: paradoxes, enhancements, and possibilities," Qualitative Research, vol. 3, pp. 321-344, 2003.

[62] A. Tong, P. Sainsbury, and J. Craig, "Consolidated criteria for reporting qualitative research (COREQ): a 32-item checklist for interviews and focus groups," International Journal for Quality in Health Care, vol. 19, no. 6, pp. 349-357, 2007.

[63] N. Britten, R. Campbell, C. Pope, J. Donovan, M. Morgan, and R. Pill, "Using meta ethnography to synthesise qualitative research: a worked example," Journal of Health Services Research \& Policy, vol. 7, no. 4, pp. 209-215, 2002.

[64] S. Atkins, S. Lewin, H. Smith, M. Engel, A. Fretheim, and J. Volmink, "Conducting a meta-ethnography of qualitative literature: lessons learnt," BMC Medical Research Methodology, vol. 8, article 21, 2008.

[65] D. Barnard, "Chronic illness and the dynamics of hoping," in Chronic Illness from Experience to Policy, S. K. Toombs, D. Barnard, and R. A. Carson, Eds., Indiana University Press, Bloomington, Ind, USA, 1995.

[66] P. Conrad, "The experience of illness: recent and new directions," in The Experience and Management of Chronic Illness, J. A. Roth, Ed., JAI Press, Greenwich, UK, 1987.

[67] S. Kaufman, "Illness, biography, and the interpretation of self following a stroke," Journal of Aging Studies, vol. 2, no. 3, pp. 217-227, 1988.

[68] W. Seymour, Bodily Alterations: An Introduction to a Sociology for Health Workers, Allen \& Unwin, Sydney, Australia, 1989.

[69] C. E. Cutrona and D. Russell, "Type of social support and specific stress: toward a theory of optimal matching," in Social Support: An Interactional View, I. G. Sarason, Ed., John Wiley \& Sons, New York, NY, USA, 1990.
[70] D. E. Jacobson, “Types and timing of social support," Journal of Health and Social Behavior, vol. 27, no. 3, pp. 250-264, 1986.

[71] R. S. Weiss, "Transition states and other stressful situations: their nature and programs for their management," in Support Systems and Mutual Help: Multi-Disciplinary Explorations, G. Caplan and M. Killilea, Eds., Grune and Stratton, New York, NY, USA, 1976.

[72] I. J. Gill, G. Wall, and J. Simpson, “Clients' perspectives of rehabilitation in one acquired brain injury residential rehabilitation unit: a thematic analysis," Brain Injury, vol. 26, pp. 909-920, 1992.

[73] G. Dixo, E. W. Thornton, and C. A. Young, "Perception of self-efficacy and rehabiltation among neurologically disabled adults," Clinical Rehabilitation, vol. 21, no. 3, pp. 230-240, 2007.

[74] J. Smith, A. Forster, and J. Young, "Cochrane review: information provision for stroke patients and their caregivers," Clinical Rehabilitation, vol. 23, no. 3, pp. 195-206, 2009.

[75] A. Bandura, Social Foundations of Thought and Action. A Social Cognitive Theory, Prentice-Hall, Englewood Cliffs, NJ, USA, 1986.

[76] D. L. Feltz and C. D. Lirgg, "Self-efficacy beliefs of athletes, teams, and coaches," in Handbook of Sport Psychology, R. N. Singer, H. A. Hausenblas, and C. Janelle, Eds., pp. 340-361, John Wiley \& Sons, New York, NY, USA, 2nd edition, 2001.

[77] F. Pajdres, "Motivational role of self-efficacy beliefs in self-regulated learning," in Motivation and Self-Regulated Learning-Theory Research and Applications, D. H. Schunk and B. J. Zimmerman, Eds., pp. 111-140, Taylor and Francis, Abingdon, UK, 2008.

[78] C. J. Barron, J. A. K. Moffett, and M. Potter, "Patient expectations of physiotherapy: definitions, concepts, and theories," Physiotherapy Theory and Practice, vol. 23, no. 1, pp. 37-46, 2007.

[79] S. Guidetti, E. Asaba, and K. Tham, "The lived experience of recapturing self-care," American Journal of Occupational Therapy, vol. 61, no. 3, pp. 303-310, 2007.

[80] F. Jones and A. Riazi, "Self-efficacy and self-management after stroke: a systematic review," Disability and Rehabilitation, vol. 33, no. 10, pp. 797-810, 2011.

[81] N. E. Mayo, S. Wood-Dauphinee, R. Côté, L. Durcan, and J. Calton, "Activity, participation and quality of life six months post stroke," Archives of Physical Medicine Rehabilitation, vol. 83, pp. 1035-1042, 2002.

[82] A. Soundy, J. Benson, H. Dawes, B. Smith, J. Collett, and A. Meaney, "Understanding hope in patients with multiple sclerosis," Physiotherapy, vol. 98, pp. 349-355, 2012. 

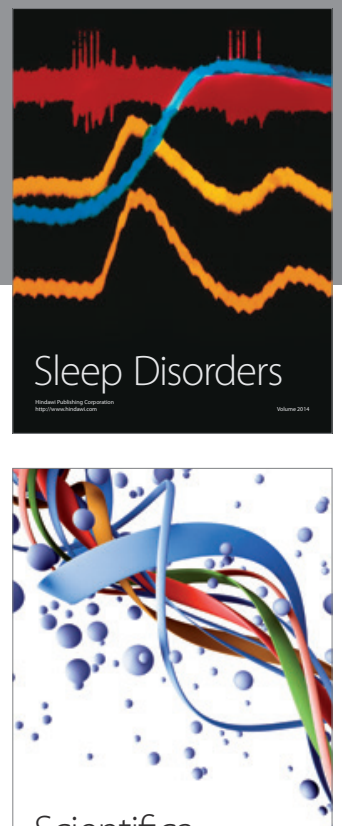

Scientifica
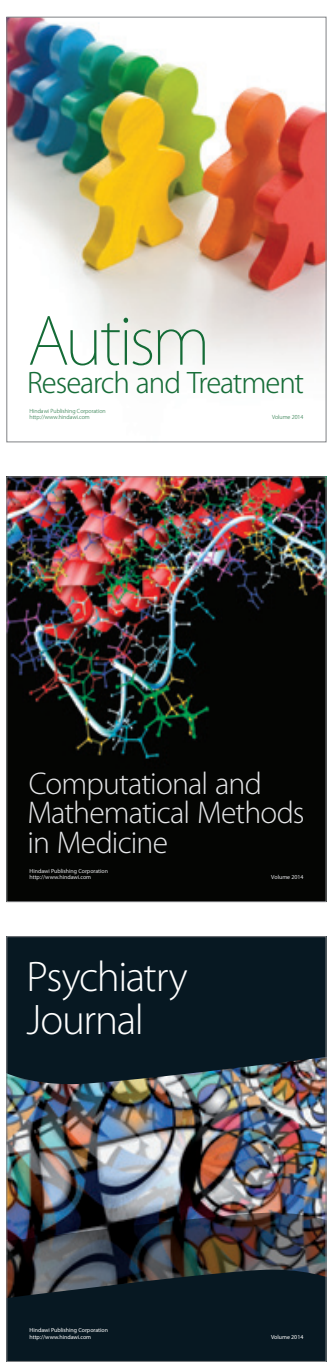
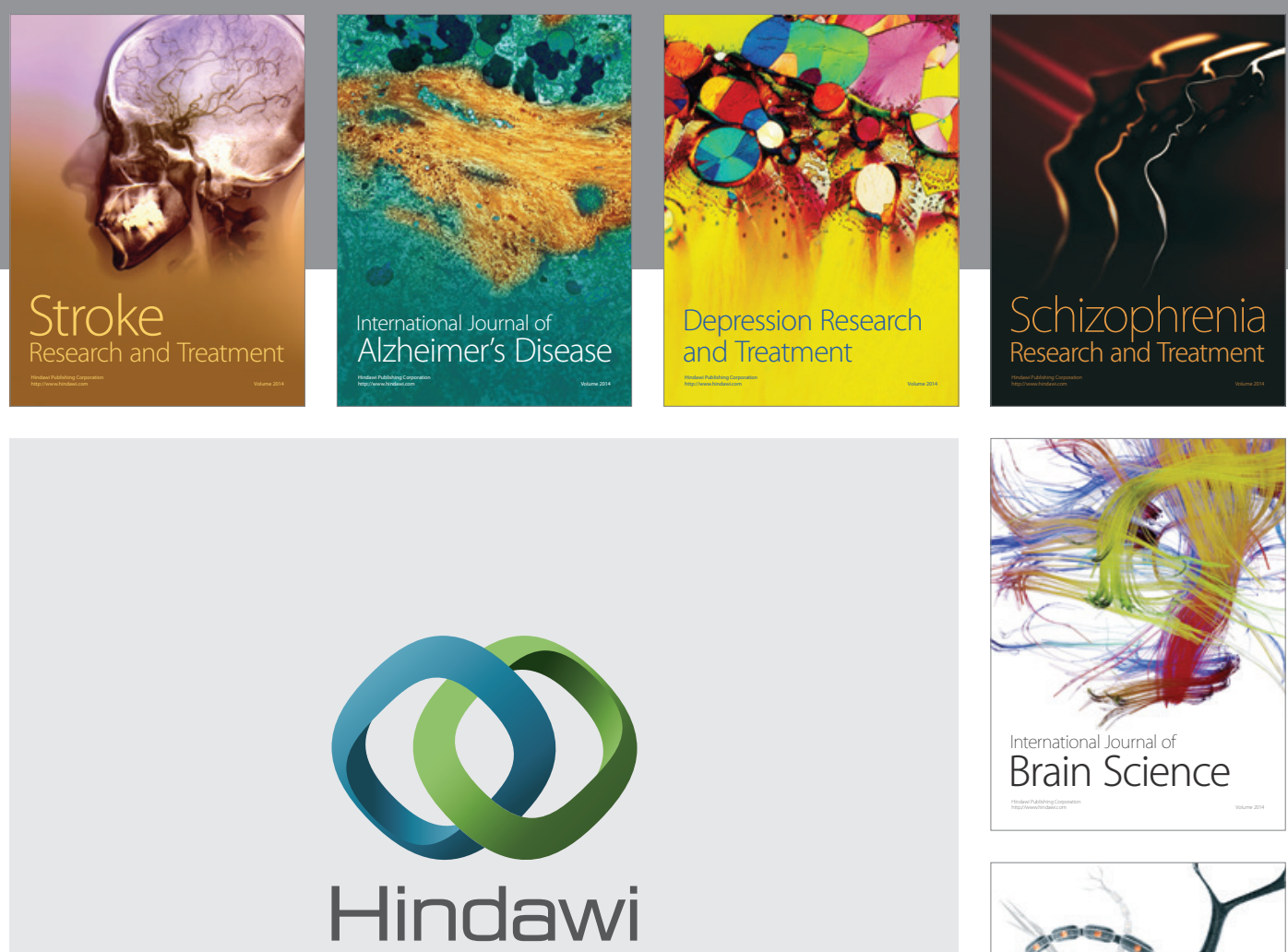

Submit your manuscripts at

http://www.hindawi.com
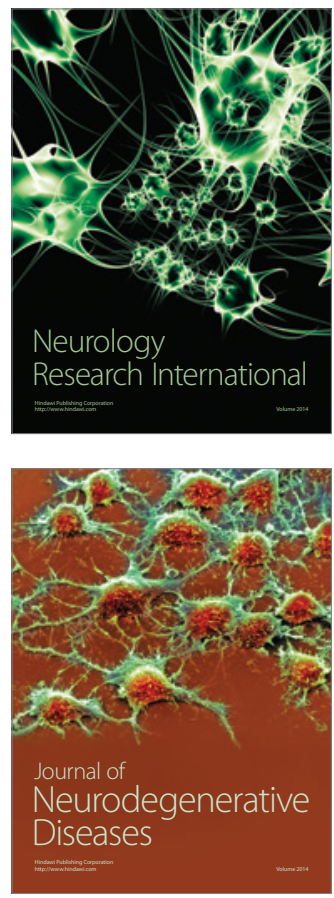

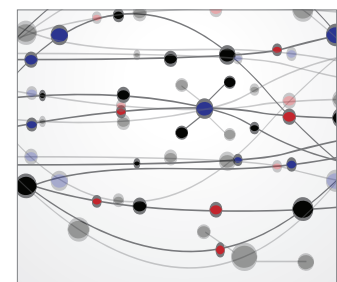

The Scientific World Journal
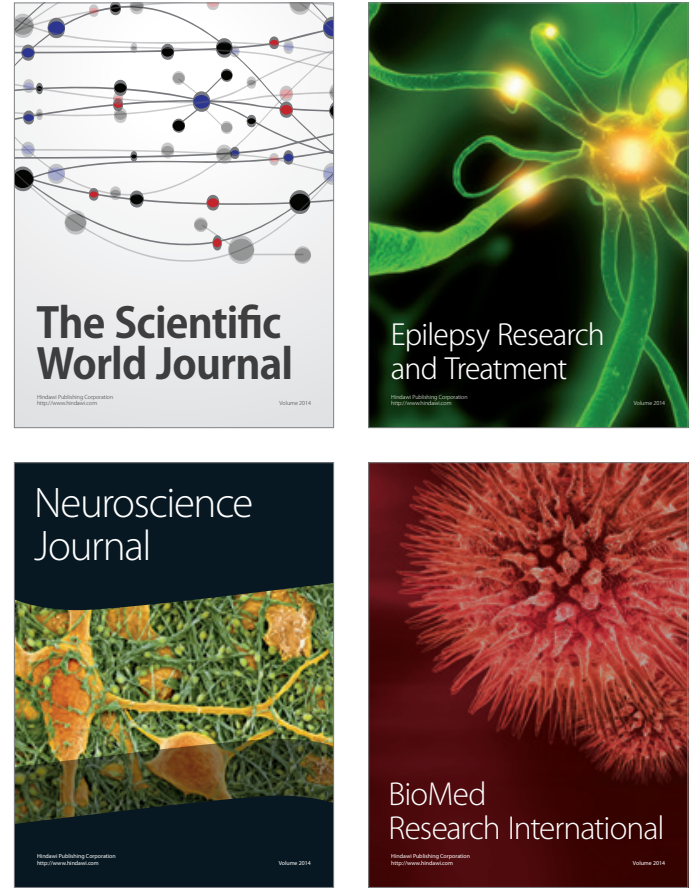

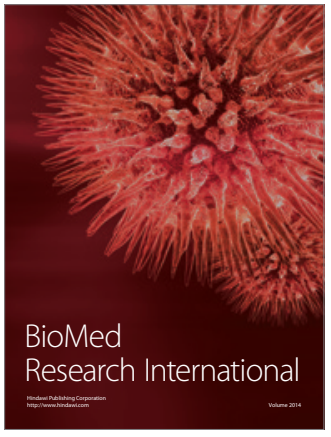

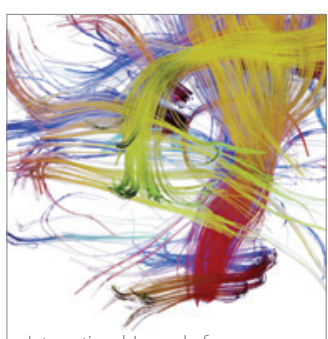

Brain Science

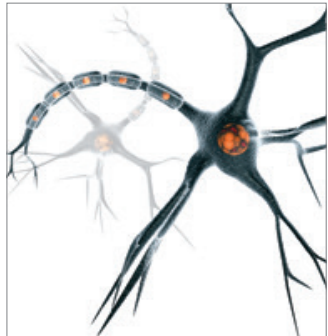

Neural Plasticity
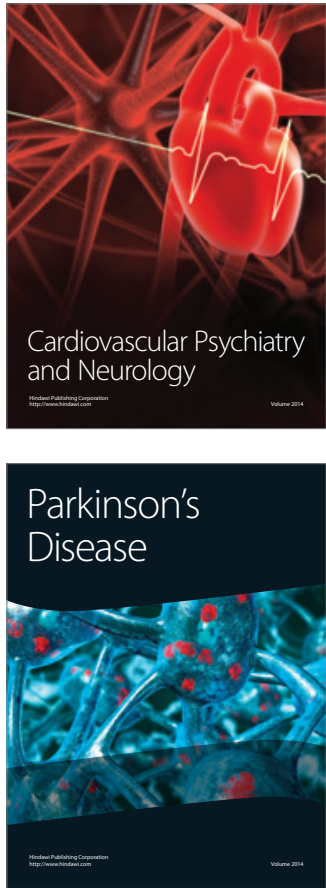